\title{
Relationship between Religious Attitude, Optimism, Spiritual Intelligence and Mental Hygiene of Post-Graduate Students of Islamic Azad University Tehran Science and Research Branch
}

\author{
Mahboubeh Ghaffari Monfared
}

Department of Psychology, Science and Research Branch, Islamic Azad University, Khouzestan, Iran Email: ghafari.sanaz@yahoo.com

Farah Naderi

Department of Psychology, Science and Research Branch, Islamic Azad University, Khouzestan, Iran

\author{
Doi:10.5901/mjss.2015.v6n6s1p208
}

\begin{abstract}
The research purpose was to assess the relationship between religious attitude, optimism, spiritual intelligence and mental hygiene of post-graduate students of Islamic Azad University, Tehran Science and Research Branch. The statistical population included 220 college students who were selected through random stratified sampling. The research used descriptivecorrelational design. The data gathering tools included General Health Questionnaire, Spiritual Intelligence Questionnaire and Life Orientation Test. Data were analyzed using Pearson correlation coefficient and multivariate regression. The results revealed a significant negative relationship between internal religious attitude, optimism spiritual intelligence, and mental health. Moreover, there existed positive relationship between external religious attitude and mental hygiene. Results of regression indicated that optimism and spiritual intelligence were good predictors of female students' mental hygiene; however, spiritual intelligence was the sole predictor of mental hygiene.
\end{abstract}

Keywords: Religious Attitude, Optimism, Spiritual Intelligence, Mental Hygiene.

\section{Introduction}

The psychological distress of the modern life and rapid social changes that are dramatically accelerated under the influence of new technological evolution and advancement can significantly affect people's mental hygiene and life quality. Psychosocial factors play a significant role in economic development, providing hygienic-social services and worthwhile efforts. Human being is becoming increasingly aware of the effects of psychological factors in his/her happiness. Feelings of security, dubiousness and apprehension about reaching the destination have taken the place of epidemic illnesses, drought and famine of the previous centuries. Studies indicate that, human beings' psychological distress and disturbance has threaten his health more than physical disorders and is fast becoming one of the main reasons of his/her hospitalization.

Psychology of hygiene attaches paramount importance to the role of coping strategies and individuals' life style in the determination of his/her physical and psychological health condition. One of the strategies that has been recently designed and pursued is religious and spiritual coping that leads to an individual's health and peace. Recent findings indicate that these copings are the sources of affective support and great tools in the interpretation of positive life events which can facilitate later copings; therefore, its employment enhances individual's health (Sadeghi et al, 2010).

Human being is a thinking creature due to his/her attitude toward problems, events, issues and subjects. One of the defining and distinctive traits is optimism. Optimism is one of the central and fundamental aspects of positive psychology. Optimists look on the bright side of every obstacle and expect good end for each challenge (Seligman et al, translated by Davar Panah, 2009).

\subsection{Literature Review}

Spiritual intelligence is one of the concepts which have been advanced and it embraces the worldwide interest of the psychologists in religion and spirituality. Spiritual intelligence synthesized the constructs of spirituality and intelligence in a 
new structure. Extensive attention to the spirituality and religious issues on one hand, and the effect of these issues on physical and psychological health and growth, on the other, necessitates the emergence of spiritual and religious aspects in individuals' lives. Some of the psychologists define spirituality as human beings' constant effort in responding to life's whys (West, 2004).

Since, each society wishes a healthy and capable generation, achieving this goal requires the health of every individual of the society and many indicators such as mental hygiene should be taken into account (Nouri and Bolhari, 1997). Studies indicate that religion and spirituality exert positive and significant effects on the mental health (Ghobari Bonab, 2007). Many of the researchers have asserted that human being feels the void, lack of purpose, lack of selfesteem, alienation toward self and others and is left helpless without religion and faith. Some of the others consider lack of faith as a reason behind psychological illnesses and employ religious and spiritual guidance for the treatment of psychological disorders (Malreb, 1930; translated by Tavakoli, 2002).

Religion plays a mediating role in affecting an individual's daily life events. A faithful person assesses many of the seemingly negative events as positive (Ghoruri, 2000). Many of the hygienic experts believe that our brains are inherently structured in a way to think positively instead of negatively. Optimism doesn't mean not accepting the responsibility of bad events and it stems from the individuals' thinking and clarifying methods about the causes and reasons of the events (Seligman, 2005).

Many of the studies indicate that optimism is directly and positively correlated to individuals' mental hygiene (Aghayi et al, 2006). Optimism is one of the main concepts of the positive psychology. This concept is in line with its colloquial application as a worthy psychological source which will bring higher degree of welfare and it's regarded as a buffer against the negative effects of stress (Scheier \& Carver, 2003). Optimism helps individuals to resist fiercely against depression which provokes the failure and stressful life events. This blessing helps individuals to achieve more success in life and work as compared to what is expected of him.

Optimism activates the immune system and causes an individual to contract less infectious disease and make fewer visits to the doctor (Seligman et al, 1995, translated by Davar Panah, 2009). Many studies have been carried out on the effect of positivism on mental hygiene and coping with problems. Positivism benefits active coping strategies. Optimists act actively using effective coping strategies. Optimists are less probable not to get involved with their goals, avoid or leave them. Evidence shows that optimism is related to physical and psychological health, life satisfaction and psychological welfare (Baldwin et al, 2008).

Optimism predicts positive attitudes and tendencies, planning for the improvement, searching for the information and restructuring the bad events. Optimists use less blame, sarcasm and determinism. They do not focus on the negative aspects of a situation and do not attempt to suppress their symptoms. Positivists accept unchangeable situations instead of escaping from them and cope with serious diseases instead of worrying about the threats to the health. Overall, positivists have better problem-solving abilities as compared to the pessimists (Mousavi Nasab, 2005).

Spiritual intelligence (SQ) is genuine and credible intelligence which covers concepts such as thinking, conceptualization and solving problems. Since the concept of spirituality has different definitions and this concept plays a major role in the definition of spiritual intelligence (SQ), it can be mentioned that cultural differences impact on people's spiritual and religious attitudes, practice, and skills related to their spiritual intelligence (SQ). The concept of spiritual intelligence (SQ) is a universal feature; however, it's meaning and how it emerges is diverse among people of different cultures (Emmons, 2009). According to Wolman (2012) spiritual intelligence (SQ) has seven components, including divinity, mindfulness, extrasensory perception, community, intellectuality, and trauma and childhood spirituality. With regard to what was mentioned above, the research purpose was to assess the relationship between religious attitude, optimism, spiritual intelligence and mental hygiene of post-graduate students of Islamic Azad University, Tehran Science and Research Branch.

\section{Method and Materials}

The statistical population included all the male and female students studying in the MA level of Islamic Azad University, Tehran Science and Research Branch. Our sample comprised 220 college students who were selected through random stratified sampling. The research used descriptive-correlational design.

The data gathering tools included General Health Questionnaire, Spiritual Intelligence Questionnaire and Life Orientation Test which will be described as following:

Religious Orientation Questionnaire: Alport and Ross designed and developed a 21-items questionnaire to assess the internal and external religious orientation in 1950. Items 1 to 12 assesses the external religious orientation from completely disagree to completely agree. The next 9 items from 13 to 21 measures external religious orientation with 
reverse responses which are scored on 5-point Likert scales from completely agree to completely disagree. This questionnaire was translated and normalized in Iran in 1999. The internal consistency was assessed by Jan Bozorgi. The Cronbach alpha was equal to .71 and the test-retest reliability equaled .74 .

Optimism Questionnaire: Scheier \& Carver (1985) designed this questionnaire. The old version of LOT was then replaced by LOT-R (Scheier et al, 1994). This test has been normalized by Khodabakhsi in 2004 in Iran. The reliability coefficient of this questionnaire using Cronbach alpha was equal to .74. This questionnaire had 6 items which measured optimistic and pessimistic attitudes and the respondents announce their agreement or disagreement with each of these statements. The test is scored on a 5-point Likert scale from completely agree to completely disagree. The items of 3, 7, and 9 are reversely scored.

Spiritual intelligence questionnaire: this test was designed, standardized and normalized by Abdollah Zadeh et al in 2008. The reliability of the test using alpha was equal to .87. The item number 12 was later eliminated and the total questionnaire had 29 items. This questionnaire is divided into 2 factors. The first factor and second factor are identified with 12 items and 17 items. The questionnaire is scored on a 5-point Likert scale from completely agree to completely disagree.

General Health Questionnare-12 (GHQ): this 12-item questionnaire distinguishes healthy and unhealthy individuals. This questionnaire was designed and developed by Goldberg and Hiller (1970). Later, this test was validated by Montazeri et al in the Hygienic Science Research Center and its internal consistency using Cronbach alpha is equal to .87. This self-assessment questionnaire takes 5 minutes to administer and evaluates an individual's psychological status during the last one month. It can be scored on 4-point Likert scale with the highest possible score of 35 . Individuals with better life condition score lower on GHQ-12.

Data were analyzed using Pearson correlation coefficient and multivariate regression.

\section{Results and Findings}

The first hypothesis: there exists significant relationship between students' internal religious attitude and their mental hygiene.

Table 1 - Simple correlation coefficient between students' internal religious attitude and their mental health

\begin{tabular}{|c|c|c|}
\hline $\mathrm{N}$ & $(\mathrm{r})$ & Level of sig. \\
\hline 220 & $0.13-$ & .050 \\
\hline
\end{tabular}

As it is seen in table 1, there existed significant and negative relationship between the internal religious attitude and their mental hygiene $(r=-0.13$ and $P<0.050)$. Therefore, the first hypothesis was confirmed. For want of a better word, increase of internal religious attitude decreases the possibility of having a disorder in the mental hygiene.

The second hypothesis: there exists significant relationship between students' external religious attitude and their mental hygiene.

Table 2 - Simple correlation coefficient between students' external religious attitude and their mental health

\begin{tabular}{|c|c|c|}
\hline $\mathrm{N}$ & $(\mathrm{r})$ & Level of sig. \\
\hline 220 & .14 & .038 \\
\hline
\end{tabular}

As observed in table 2, there existed significant and positive relationship between the external religious attitude and their mental hygiene ( $r=-0.14$ and $\mathrm{P}<0.038)$. Therefore, the second hypothesis was confirmed too. For want of a better word, increase of internal religious attitude increases the possibility of having a disorder in the mental hygiene.

The third hypothesis: there exists significant relationship between optimism and their mental hygiene.

Table 3 - Simple correlation coefficient between students' optimism and their mental health

\begin{tabular}{|c|c|c|}
\hline $\mathrm{N}$ & $(\mathrm{r})$ & Level of sig. $) \mathrm{p}($ \\
\hline 220 & $0.25-$ & 0.0001 \\
\hline
\end{tabular}

As observed in table 3, there existed significant and negative relationship between the optimism and their mental hygiene $(r=-0.25$ and $P<0.0001)$. Therefore, the third hypothesis was also confirmed. For want of a better word, increase of optimism decreases the possibility of having a disorder in the mental hygiene. 
The fourth hypothesis: there exists significant relationship between spiritual and their mental hygiene.

Table 4 - Simple correlation coefficient between students' spiritual intelligence and their mental health

\begin{tabular}{|c|c|c|}
\hline $\mathrm{N}$ & $(\mathrm{r})$ & Level of sig. \\
\hline 220 & -0.29 & .050 \\
\hline
\end{tabular}

As observed in table 4, there existed significant and negative relationship between the spiritual intelligence and their mental hygiene $(r=-0.25$ and $P<0.0001)$. Therefore, the fourth hypothesis was confirmed. For want of a better word, increase of spiritual intelligence decreases the possibility of having a disorder in the mental hygiene.

The fifth hypothesis: there exists multivariate relationship between the students' internal religious attitude, external religious attitude, optimism, spiritual intelligence and mental health.

Table 5 - Multivariate correlation coefficients of prediction variables (internal religious attitude, external religious attitude, optimism, spiritual intelligence) and mental health

\begin{tabular}{|c|c|c|c|c|c|c|c|c|c|}
\hline 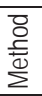 & Criterion variable & Prediction variables & $\mathrm{R}$ & R2 & $\mathrm{F}$ & $P$ & $\beta$ & $\mathrm{T}$ & $P$ \\
\hline \multirow{5}{*}{ 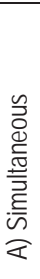 } & \multirow{5}{*}{ 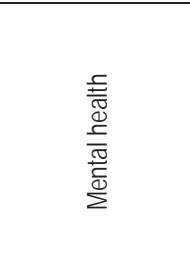 } & Internal religious attitude & \multirow{5}{*}{0.35} & \multirow{5}{*}{0.12} & \multirow{5}{*}{7.42} & \multirow{5}{*}{0.0001} & 0.01 & 0.178 & 0.859 \\
\hline & & External religious attitude & & & & & 0.07 & .070 & .295 \\
\hline & & Optimism & & & & & -0.18 & -2.64 & .009 \\
\hline & & Spiritual intelligence & & & & & $0.24-$ & -3.29 & .001 \\
\hline & & & & & & & & & \\
\hline \multirow{3}{*}{ 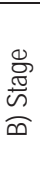 } & \multirow{3}{*}{ 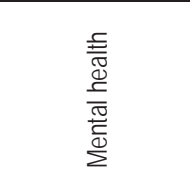 } & 1- spiritual intelligence & 0.29 & .08 & 20.29 & 0.0001 & $0.29-$ & -4.50 & .0001 \\
\hline & & \multirow[b]{2}{*}{ 2- optimism } & \multirow[b]{2}{*}{0.34} & \multirow[b]{2}{*}{.12} & \multirow[b]{2}{*}{14.36} & \multirow[b]{2}{*}{0.0001} & $0.24-$ & -3.66 & .0001 \\
\hline & & & & & & & $0.18-$ & -2.79 & .006 \\
\hline
\end{tabular}

As observed in table 5, prediction regression of students' mental hygiene on students' internal religious attitude, external religious attitude, optimism and spiritual intelligence was significant $(\mathrm{F}=7.42, \mathrm{P} \leq 0.0001)$. Therefore, the fifth hypothesis was confirmed. The variable of optimism with Beta coefficient of .18 and the variable of spiritual intelligence with Beta coefficient of .24 could negatively and significantly predict the students" mental hygiene. Moreover, the R2 value indicated that $12 \%$ of the variance of students' mental hygiene could be explained by the mentioned variables. Regression analysis also indicated that spiritual intelligence and optimism could be the predictors of students' mental hygiene.

Table 6 - Multivariate correlation coefficients of prediction variables (internal religious attitude, external religious attitude, spiritual intelligence) and optimism

\begin{tabular}{|c|c|c|c|c|c|c|c|c|c|}
\hline 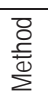 & Criterion variable & Prediction variables & $\mathrm{R}$ & R2 & $\mathrm{F}$ & $P$ & $\beta$ & $\mathrm{T}$ & $\mathrm{P}$ \\
\hline \multirow{3}{*}{ 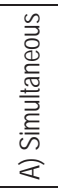 } & \multirow{3}{*}{ 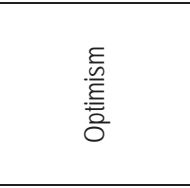 } & Internal religious attitude & \multirow[b]{3}{*}{.30} & \multirow[b]{3}{*}{.09} & \multirow[b]{3}{*}{6.99} & \multirow[b]{3}{*}{.0001} & .07 & 0.996 & 0.321 \\
\hline & & External religious attitude & & & & & -0.11 & -1.61 & 0.108 \\
\hline & & Spiritual intelligence & & & & & 0.22 & 3.02 & .003 \\
\hline 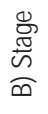 & 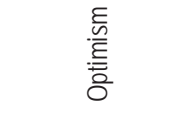 & Spiritual intelligence & .26 & .07 & 16.54 & .0001 & 0.26 & 4.06 & 0.0001 \\
\hline
\end{tabular}


As observed in table 6, prediction regression of students' prediction variables of internal religious attitude, external religious attitude, spiritual intelligence and optimism was significant $(\mathrm{F}=6.99, \mathrm{P} \leq 0.0001)$. Therefore, the sixth hypothesis was confirmed. The variable of spiritual intelligence with Beta coefficient of .22 can positively and significantly predicted the students' optimism. Moreover, the R2 value indicated that $9 \%$ of the variance of students' optimism would be explained by the mentioned variables. Regression analysis also indicated that the variable of spiritual intelligence could be the predictors of students' optimism.

Table 7 - Results of multivariate variance (MANOVA) on the scores of male and female students' internal religious attitude, external religious attitude, optimism, spiritual intelligence and mental hygiene

\begin{tabular}{|l|c|c|c|c|c|}
\hline Test & Value & DF Hypothesis & DF Error & F & Level of sig.) $p($ \\
\hline Pillai's trace & .030 & 5 & 211 & 1.31 & .260 \\
\hline Wilks' lambda & .973 & 5 & 211 & 1.31 & .260 \\
\hline Lawley-Hotelling trace & .031 & 5 & 211 & 1.31 & .260 \\
\hline Roy's largest root & .031 & 5 & 211 & 1.31 & .260 \\
\hline
\end{tabular}

As observed in table 7, the significance level of the entire test indicated that there existed no significant difference between the dependent variables (internal religious attitude, external religious attitude, optimism, spiritual intelligence and mental hygiene). Put it differently, male and female students had similar internal religious attitude, external religious attitude, optimism, spiritual intelligence and mental hygiene.

\section{Discussion and Conclusion}

The research purpose was to assess the relationship between religious attitude, optimism, spiritual intelligence and mental hygiene of post-graduate students of Islamic Azad University, Tehran Science and research branch. The results of the present research and the confirmation of the first hypothesis was in line with the research results carried out by Sanders (2003), Kazemian and Mehrabi Zadeh (2009), Najjar Asl (2005). The confirmation of the second hypothesis was in line with the research results carried out by Perry (2006) and Shahbazi (2007). The confirmation of the third hypothesis was in harmony with the research results carried out by Baldwin et al (2008), Hossein Zadeh (2008), Kazemi (2009) and Aghayi et al (2006). Confirmation of the fourth hypothesis was consistent with the research results carried out by Hamid, Keikhosravani, Baba Miri and Dehghani (2012). Finally, the confirmation of the fifth hypothesis was in line with the research results done by Zare Nouri and Farid Far (2005). In the explanation of these findings, it could be concluded that feelings of belonging to a high power and hoping for the God's help in stressful life conditions were resources by which individuals are confronted with less pathological problems and enjoy more psychological hygiene. Spiritual and religious attitudes and beliefs have strong effect in giving meaning to individuals' lives and bring about hope and positive attitude which results in their internal peace. However, it should be mentioned that women have more time for religious activities (Beti - Hallahme \& Argyle, 1997).

Religion is amongst the most crucial columns of the society and guaranteeing its identity and cohesion. Individual who have higher capacity for better adjustment with psychological problems have better psychological and mental hygiene. Individuals who have external religious orientation know their religious commitment as a tool in reaching power and positions. These individuals regard religion as a tool for their lives and cannot benefit worthwhile aspects of religion in their mental hygiene. Therefore, the main function of religion is overlooked amongst such individuals and they may suffer from the void, meaninglessness and hopelessness against limitations and psychological pressures (Tavakkoli, 2003).

On the other hand, optimism refers to hope-raising expectations that exist in a specific position. This expectation can be generalized to other life conditions and it's related to the hygienic indices and mental health. Optimistic people think about the solutions not the problems. When the solution is highlighted, less stress is also created. Optimistic individuals attribute problems to temporary and external causes; they are happier and healthier and take participation in health enhancing preventive programs.

A balanced life requires the gratification of mental, affective and physical needs. We should consider our spiritual and mental requirements, as well; spiritual intelligence can integrate our internal and spiritual life with our external and work life and facilitate finding the meaning of life. Spiritual intelligence refers to a combination of abilities and capacities that gives rise to increased level of individuals' adjustment and mental health. Moreover, spiritual intelligence is a repository of psychological adjustment capabilities based on non-material aspects, which provides for new perspective toward life, problem-solving ability and a more stable self with decreased level of anxiety and stress. An individual who 
holds onto his faith knows God better and is committed to God's orders that enhance his spiritual intelligence. Weak spiritual intelligence is a vulnerable feature in the increase of mental disorders. Individuals who develop psychological and mental deficiencies and disorders when they perceive their limits, feel lonely, lose their interest and energy. Psychological disorder is a normal response to life pressure; however, it is more easily eliminated in individuals who are spiritually intelligent. Mental pressure is a simple psychological mechanism which encompasses affective and stimulating feedbacks against threatening and undesirable factors. Individual who are weak in spiritual intelligence feel exhausted and have limited physical activity and are not usually in the good mood.

\section{References}

Abdollah Zadeh, R., Keshmiri, M., \& Arab Ameri, F. (2008). Logo-cognitive role of accidents in decreasing psychological traumas. Journal of University, 41, 8-29.

Abedi, F., \& Rastegar, Z. (2008). Relationship between spiritual intelligence and personality traits among the individuals aged 19-50 residing in Sari. MA thesis. Behshahr PNU.

Aghayi, A., et al (2003). Relationship between optimism, pessimism and psychological health amongst the adults of Isfahan City. Journal of Knowledge and Research in Psychology, 33, 117-130.

Allport, G. (1963). The person in psychology. Boston, Beacon Press.

Aryan, K. (2000). Relationship between having faith and psychological health among the individuals residing in Canada. MA thesis. Allameh Tabatabaei University.

Baldwin, D. R., Kennedy, D. L., \& Armata, P. M. (2008). De -stressing mommy: ameliorative association with dispositional optimism and resiliency. Journal of Stress and Health, 24, 393-400.

Brown, L. B. (1973). Psychology and religion. Baltimore, MD: Penguin. Help Guild org, (2004). Mental and Emotional Health.

Carr, A. (2004). Positive psychology. Translated by Hasan Pasha Sharifi and Jafar Najafi Zand, (2006). Tehran: Sokhan Publication.

Carver, C. S., \& Gaines, J.G. (1985).Optimism, Pessimism, and Postpartum depression. Cognitive Therapy and Research, 11, 449-462.

Carver, C. S., Scheire, M. F. (2003). On the self-regulation of behavior. New York: Cambridge University Press.

Francis, L. J., Robbins, M., Lewis, C. A., Quigley, C. F., \& Wheeler, C. (2002). Religiosity and general health among undergraduate students: A response to O Connor, Cob and O Connor 2003. Personality and Individual Differences, 37, 485-494.

Ghobari Bonab, B. (2007). Religious beliefs and their effects on mental hygiene. Journal of Thought and Behavior, 1(4).

Gholami, F. (2008). Relationship between religious attitudes and pre-university students' mental health. MA thesis. Islamic Azad University, Central Tehran Branch.

Ghorvi, J (2000). Islamic approach in the process of depression treatment. Journal of Ma'refat, 2.

Hossein Zadeh Mahdavi, M. (2008). Effectiveness of positive thinking training, optimism and group cognitive-behavioral approach in female high-school adolescents' mental health. MA thesis. Allameh Tabatabaei University.

Hosseini Isfahani, F. (2011). An investigation into the role of religion and religious beliefs in the mental health of female high-school students studying in Kahrizak City in the year ran from 2010 to 2011. MA thesis. Islamic Azad University, Tehran Central Branch.

Joseph, S., \& Linley, D. A. (2006). Positive therapy: A meta- therapy for positive psychological practice.

Kazemi, F. (2009). Comparison of attributional styles, life orientation, general health and psychological well-being in mothers of pessimistic and optimistic children studying in the fifth grade of elementary school and effectiveness of attributional retraining in mothers and children on pessimistic children psychological immunology. Ph.D. thesis. Allameh Tabatabaei University.

Khoda Rahimi, S., and Jafari, S. G. (2004). Role of religion on mental health, psychotherapy and clinical psychology. Journal of the Principles in Mental hygiene. 12-25.

Mirshamsi, F. (2009). Relationship between spiritual intelligence and quality of life among technology-engineering students studying in Azad and governmental universities of Yazd in the academic year ran from 2008 to 2009. MA thesis. Allameh Tabatabaei University.

Mousavi Nasab, S. M. H. (2005). Optimism-pessimism, assessment of stress and coping strategies among the adolescents. MA thesis. Shiraz University.

Nolen - Hoeksema, S., Girgus, J. S., \& Seligman, M. E. P. (1986).Learned helplessness in children: A longitudinal study of depression, achievement, and explanatory style. Journal of Personality and Social Psychology, 51, 435 -442.

Pargament, K. I., Olsen, H., Reilly, B., Falgout, K., et al. (1992). God helps me. The relationship of religious orientations to religious coping with negative life events. Journal for the Scientific Study of Religion, 31(4), 504-513.

Peterson, C. (2006). A primer in positive psychology. New York: Oxford University Press.

Seligman, M. A. P. (1995). An optimistic child. Translated by Davar Panah, F. (2009). 1st edition. Tehran: Roshd Publication.

Seligman, M. E., Steen, T. A., Park, N., Peterson, C. (2005). Positive psychology progress: Empirical validation of interventions. Journal of American Psychologist, 60, 410-421.

Snyder, C. R., \& Lopez, S. J. (2007). Positive psychology: The scientific and practical explorations of human strengths. New York: Sage Publication Inc.

Sohrabi, F. (2008). Fundamental of spiritual intelligence. Quarterly of mental health. 1(1), 14-18.

West, V. (2008). Spirituality and psychotherapy. Translated by Shahriar Shahidi and Soltanali Shirafkan. (2008). Tehran: Roshd Publication. 